\title{
PEMIKIRAN FILOSOFIS PENDIDIKAN IBNU SINA DAN IMPLIKASINYA PADA PENDIDIKAN ISLAM KONTEMPORER
}

\author{
Aris Try Andreas Putra \\ IAIN Kendari, Sulawesi Tenggara \\ Email: aristryandreasputra@ymail.com
}

\begin{abstract}
The central issue faced by the Muslim world, especially Islamic education today is the inception of secular science. Science is presented in the form of dichotomy. To pave the issue of Islamic education, the required reconstruction of the educational philosophy of Islam. In order to answer this question the author tries to present the ideas of Ibn Sina were rational religious scented. Ibn Sina is a figure of Islamic education which produces a lot of work in various fields of science, especially medicine and education, Ibn Sina emphasizes education was beld by non-dichotomous. Educational purposes thinks should be directed towards preparing a person to be able to live in the community together with the conduct of expertise chosen according to their talents and potentials. Therefore, the curriculum is conceived by Ibn Sina conceived and developed based on the stage of growth and development of the Child.
\end{abstract}

Keywords: Thinking Education, Ibnu Sina, and Implications

\section{PENDAHULUAN}

Pendidikan Islam merupakan usaha yang menciptakan dan membentuk manusia yang baik dan lebih bermakna dalam kehidupan dunia dan mempersiapkannya untuk kehidupan ukhrawi. Secara konseptual pendidikan Islam diawali oleh landasan - landasan ideologis - filosofis untuk pelaksanaannya/ implementasinya pada latar social-budaya. Pembaharuan falsafah Islamiyah dalam dunia pendidikan dewasa ini menjadi sangat urgen untuk dilakukan dalam rangka menciptakan pendidikan yang berkualitas seperti yang telah diarahkan oleh kitab suci. Rekonstruksi falsafah harus dimulai dari aspek ontologis, epistemologi dan axiologi, dalam upaya menjawab tantangan pendidikan Islam saat ini. Problem adanya dikotomi antara ilmu-ilmu agama dan ilmu umum menyebabkan tidak berkembangnya ilmu pengetahuan dan terjadinya krisis metodologi keilmuan. Krisis yang terjadi dalam dunia pengetahuan dan pendidikan Islam saat ini mengakibatkan tradisi keilmuan menjadi statis, 
sehingga pendidikan Islam belum menunjukkan perannya secara maksimal dalam menciptakan peradaban yang maju, seperti masa kejayaan Islam pada abad 8-13 M silam. Peradaban Islam tidak lain adalah suatu hasil akumulasi perjalanan pergumulan penganut agama Islam ketika berhadapan dengan proses dialektis antara "normativitas" ajaran wahyu yang permanen dan "historisitas" pengalaman kekhalifaan manusia dimuka bumi yang selalu berubah-ubah. ${ }^{1}$

Untuk melahirkan pendidikan yang berkualitas, harus berangkat pada metodologi pikir yang kuat dan landasan filosofis-epistemologi yang handal. Berdasarkan paradigma humanis-religious harus mempertimbangkan akal sehat, individualism menuju kemandirian, pendidikan pluralis, anti-dikotomi, semangat menggali ilmu yang tulus, fungsionalisme, mengalahkan simbolisme, serta penghargaan dan sanksi. Pendidkan Islam sebagai tujuan, alat perubahan, dan transformasi sosial sudah semestinya diarahkan untuk mengakomodasi budaya lokal dan berorientasi kedapan, yakni yang religious dan modern. ${ }^{2}$

Namun demikian, masih terdapat berbagai persoalan umat dan pendidikan Islam sekarang ini yang menurut Assegaf berpangkal pada pada empat hal sebagai berikut: 1) lemahnya visi (lack vision); 2) penekanan pada kesalehan individual sehingga menyebabkan ketertinggalan teknologi; 3) keilmuan yang dikotomis; dan 4) pola pikir normatif-deduktif. ${ }^{3}$ Keempat hal tersebut harus dicari jalan keluarnya sehingga umat dan pendidikan Islam dapat mengalami perkembangan, kemajuan, dan kejayaan kembali. Dalam hal ini, pemikiran filosofis Ibnu Sina menurut penulis masih sangat relevan untuk diimplementasikan dan mengatasi krisis dan kemandekan dalam pendidikan Islam tersebut. Makanya perlu dilakukan tinjauan reformasi pendidikan baik secara filosofis, epistemologi agar terwujud pendidikan Islam yang sesuai dengan tuntunan wahyu.

Oleh karena itu, muslim sejati hendaknya menerjemahkan, dan melaksanakan pendidikan Islam berbasis landasan ontologis, epistemologis dan aksiologis berdasarkan landasan al-qur'an dan as sunah. Seseorang yang mengkaji Islam dari sumbernya al-Qur'an dan al-Hadits dengan kesadaran yang mendalam akan mengeluarkan hasil pikiran yang universal mengenai sesuatu hal, baik filsafat wujud, pengetahuan, dan filsafat nilai. Hal inilah yang

${ }^{1}$ Amin Abdullah, Falsafah Kalam di Era Postmodernisme (Yogyakarata: Pustaka Pelajar), 2009), hlm. 3.

${ }^{2}$ Abdurrahman Mas'ud, Menggagas Format Pendidikan Nondikotomik (Yogyakarta: Gama Media, 2007), hlm. 229.

${ }^{3}$ Abd. Rachman Assegaf, Filsafat Pendidikan Islam: Paradigma Baru Pendidikan Hadhari Berbasis Integratif-Interkonektif (Jakarta: PT RajaGrafindo Persada, 2014), hlm. 1 
akan diperlukan dalam pendidikan Islam. ${ }^{4}$ Sebagai salah satu upaya perbaikan pendidikan Islam maka tulisan ini akan menyajikan konsep pemikiran filosofis Ibnu Sina dan implikasinya dengan pendidikan Islam masa kini.

\section{PEMIKIRAN IBNU SINA TENTANG PENDIDIKAN ISLAM Biografi Ibnu Sina $(980-1038 \mathrm{M})$}

Ibnu Sina merupakan tokoh pemikir muslim yang banyak menguasai bidang ilmu pengetahuan (baik itu ilmu-ilmu agama, sains, kedokteran dan Humaniora). Ibnu Sina nama lengkapnya adalah Ali al-Husien bin Abdullah al- Hasan bin Ali bin Sina. Ia dilahirkan di desa Afsyanah, dekat Bukhara, di kawasan Asia Tengah pada tahun $370 \mathrm{H}$ dan meninggal dunia di Hamadzan pada tahun $428 \mathrm{H}(1038$ M) dalam usia 57 tahun $^{5}$ dan Negara-negara barat namanya lebih dikenal dengan sebutan Avicena. Ia dilahirkan di Persia pada bulan Syafar 370 H/980 M. Namun orang Turki, Persia dan Arab mengklaim Ibnu Sina sebagai bangsanya. Hal ini dikarenakan ibunya berkebangsaan Turki, sedangkan ayahnya peranakan Arab. Ayahnya tinggal di kota Balkh, tetapi beberapa tahun setelah lahirnya Ibnu Sina, keluarganya pindah ke Bukhara karena ayahnya menjadi gubernur di suatu daerah di salah satu pemukiman Daulat Samaniyah pada masa pemerintahan Amir Nuh ibn Mansur. ${ }^{6}$

Pada usia 10 tahun ia telah menyelesaikan pelajaran al-Qur'an, sastra dan bahasa Arab. Kemudian ia belajar ilmu fiqh pada seorang guru bernama Ismail yang terkenal sebagai orang yang hidup zubud. Di samping itu, ia belajar metematika dan ilmu ukur pada 'Ali Abu 'Abdullah an- Natili. Setelah itu ia belajar sendiri dengan membaca berbagai buku, termasuk buku Syarb sehingga menguasi ilmu semantik. Tidak ketinggalan pula ia mempelajari buku Ocledus mengenai ilmu ukur dan buku-buku tentang ilmu kedokteran. Dalam usia 18 tahun ia telah selesai mempelajari semua ilmu tersebut. ${ }^{7}$

Ibnu Sina merupakan tokoh yang sangat produtif dalam menghasilkan karya. Beliau dikenal dengan bapak kedokteran, farmasi, astronomi. Salah satu kitab yang terkenal adalah Al-Qanun fi al-Tibb. Kitab ini adalah buku yang berisi tentang ilmu kedokteran orang Barat menyebut buku ini dengan Canon of Medicine. Buku ini telah diterjemahkan oleh Gerard of Cremona pada abad

${ }^{4} \mathrm{Al}-$ Syaibany, Filsafat Pendidikan Islam, terj. Hasan Langgulung (Bulan Bintang, Jakarta, 1979), hlm. 40

${ }^{5}$ Philip K. Hitti, History of The Arab, (ed). X (Great Britain: Oxford University Press, 1974), hlm. 367

${ }^{6}$ Muhammad Tolhah Hasan, Dinamika Pemikiran tentang Pendidikan Islam (Jakarta: Lantabora Press, 2006), hlm. 116

${ }^{7}$ Ahmad Fuad al- Ahwani, Filsafat Islam (Jakarta: Pustaka Firdaus, 1997), hlm. 84 
ke-11 dengan judul Canon yang diterbitkan di Roma pada tahun 1593. Kitab ini telah menjadi rujukan diberbagai universitas Barat hingga abad ke-15 dan juga dijadikan sebagai ensiklopedi kedokteran. ${ }^{8}$ Ibnu Sina wafat pada usia 58 tahun, tepatnya pada tahun $980 \mathrm{H} / 1037 \mathrm{M}$ di Hamadan, Iran, karena penyakit maag yang kronis. Ia wafat ketika sedang mengajar di sebuah sekolah. ${ }^{9}$

Hubungannya dengan konsep pendidikan Ibnu Sina sedikit banyak memberikan rumusan konsep dan tujuan pendidikan Islam, kurikulum pendidikan Islam, konsep pendidik yang dituliskan dalam sebuah kitabnya Al-Siyasah fiy al-Tarbiyah, atau dalam bahasa Indonesianya adalah kebiijakan dalam pendidikan atau politik dalam pendidikan.

\section{Konsep Pendidikan dan Tujuannya Menurut Ibnu Sina}

Ibnu Sina adalah tokoh pemikir Muslim yang memadukan antara dimensi rasional dan religiusitas. Keduanya adalah hal yang saling mendukung dalam memecahkan persoalan dan realitas kehidupan. Fenomena kehidupan manusia dan fenomena alam merupakan realitas yang harus dimaknai dengan menggunakan sudut pandang yang beragam. Pendekatan tunggal dan sikap tidak meneruma pendekatan baru akan menjadikan ilmu pengetahuan tidak akan kaya. Menurut Ibnu Sina ilmu terbagi menjadi dua, yaitu ilmu yang tak kekal dan ilmu yang kekal (hikmah). Ilmu yang kekal dipandang dari perannya sebagai alat dapat disebut logika. Tapi berdasarkan tujuannya, maka ilmu dapat dibagi menjadi ilmu yang praktis dan yang teoritis. Ilmu teoritis seperti ilmu kealaman, matematika, ilmu ketuhanan dan ilmu Kulli. Sedangkan ilmu yang praktis adalah ilmu akhlak, ilmu pengurusan rumah, ilmu pengurusan kota dan ilmu nabi (shari'ab). ${ }^{10}$

Ibnu Sina mengatakan bahwa akal itu wajib dikembangkan dan itulah sebenarnya tujuan akhir dari pendidikan. ${ }^{11}$ Akal merupakan salah satu instrument pokok dalam mengurai kekusutan fenomena yang belum ditemukan benang merahnya. Akal diperlukan dalam rangka membuka tabir pengetahuan.

Tujuan pendidikan menurut Ibn Sina harus diarahkan pada upaya mempersiapkan seseorang agar dapat hidup di masyarakat secara bersama-sama dengan melakukan pekerjaan atau keahlian yang dipilihnya sesuai dengan bakat,

${ }^{8}$ Philip K. Hitti, History of The Arab,..... hlm. 368

${ }^{9}$ Imam Tholkhah \& Ahmad Barizi, Membuka Jendela Pendidikan: Mengurai Akar Tradisi dan Integrasi Keilmuan Islam, (Jakarta: PT Raja Grafindo Persada, 2004), hlm. 250

${ }^{10} J a l a l u d d i n$, Filsafat Pendidikan Islam, (Jakarta: PT. Raja Grafindo Persada, 1996), hlm. 136

${ }^{11}$ Hasan Langhulung, Manusia dan Pendidikan, cet. III. (Jakarta: Pustaka al-Husna, 1995), hlm. 106. 
kesiapan, kecenderungan dan potensi yang dimilikinya. ${ }^{12}$ Selanjutnya Ibnu Sina dalam Nata mengatakan bahwa tujuan pendidikan itu harus diarahkan pada pengembangan seluruh potensi yang dimiliki seseorang ke arah perkembangan yang sempurna, yaitu perkembangan fisik, intelektual dan budi pekerti dalam rangka menciptakan insan kamil. ${ }^{13}$

Jika penulis gambarkan maka potensi manusia yang harus dipertajam dan dikembangkan dalam proses pendidikan adalah seperti berikut:

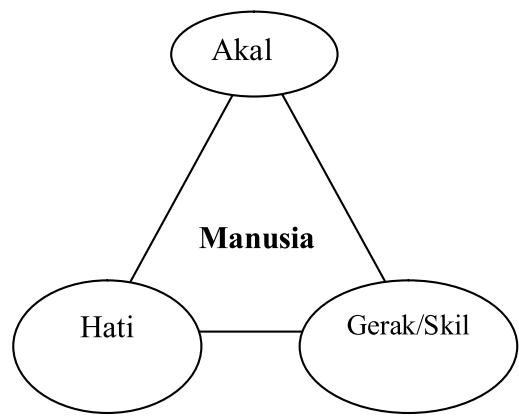

\section{Gambar 1. Segitiga Potensi Manusia yang dikembangkan dalam Proses Pendidikan Islam}

\section{Keterangan:}

a) Akal : Daya pikir, ouputnya adalah pengetahuan/kognitif

b) Hati : Daya rasa, perasaan/kemampuan afektef

c) Gerak/Skil : Mengahasilkan keterampilan/kemampuan psikomotirik

\section{Konsep Kurikulum Pendidikan Menurut Ibnu Sina}

Walaupun tidak secara formal Ibnu Sina menyebut term (istilah) kurikulum, namun demikian penulis dapat menggambarkan kurikulum dan materi ilmu pengetahuan yang harus diajarkan menurut Ibnu Sina. Materi pelajaran merupakan disiplin ilmu yang akan membantu peserta didik untuk mengisi ruang kosong dalam dirinya dan sekaligus membantu mengembangakan potensinya tersebut. Ibnu Sina membagi tingkatan materi ilmu pengetahuan yang harus dilalui anak didik harus berdasarkan tahap perkembangan dan usia pertumbuhan anak.

${ }^{12} \mathrm{Abu}$ 'Ali al-Husin ibn 'Ali Ibn Sina, Al-Siyasah fiy al-Tarbiyah, (Mesir: Dar al-Ma'arif, 1994), hlm. 1218.

${ }^{13}$ Abuddin Nata, Pemikiran Para Tokob Pendidikan Islam: Seri Kajian Filsafat Pendidikan Islam, cet. II, (Jakarta: Rajawali Press, 2001), hlm. 67-68 


\section{Kurikulum Usia 3 (tiga) S/d 5 (lima) Tahun}

Menurut Ibn Sina, diusia ini perlu diberikan mata pelajaran olah raga, budi pekerti, kebersihan, seni suara, dan kesenian. Olahraga sebagai pendidikan jasmani, Ibnu Sina memiliki pandangan yang banyak dipengaruhi oleh pandangan psikologinya. Menurutnya ketentuan dalam berolahraga harus disesuaikan dengan tingkat perkembangan usia anak didik serta bakat yang dimilikinya. ${ }^{14}$ Ibnu Sina juga mengklasifikasi olah raga mana saja yang memerlukan dukungan fisik yang kuat serta keahlian; dan mana pula olahraga yang tergolong ringan, cepat, lambat, memerlukan peralatan dan sebagainya. Menurutnya semua jenis olahraga ini disesuaikan dengan kebutuhan bagi kehidupan anak didik. ${ }^{15}$ Pendidikan olahraga dan jasmani menjadi instrument untuk memicu tumbuh sehat anak dan melatih keseimbangan gerak tubuh agar berjalan secara seimbang. Menurut penulis pendidikan olahraga dan jasmani harus disesuaikan dengan kebutuhan anak dan materinya disesuaikan dengan tingkat kesulitan dan bahayanya perlu dipertimbangkan oleh pendidik. Pendidikan olah raga dan seni dimaksudkan untuk merangsang kreavifitas peserta didik sejak dini. Pengawasan yang ketat dalam mata pelajaran olahraga menjadi salah satu usaha preventif dalam mencegah terjadinya kecelakaan pada anak.

\section{Kurikulum Usia 6 (enam) S/d 14 (empat belas) Tahun}

Pelajaran untuk anak usia 6 sampai 14 tahun menurut Ibnu Sina adalah mencakup pelajaran membaca dan menghafal al-Qur'an, pelajaran agama, pelajaran sya'ir, dan pelajaran olahraga. ${ }^{16}$ Pada usia Ibnu Sina telah berkeyakinan bahwa pelajaran menghafal boleh diajarkan. Hal ini tidak serta merta ditelorkan tanpa alasan yang jelas oleh Filosof dan Ilmuwan multi talenta ini. Menurut catatan sejarah Ibnu Sina telah mampu membaca Al-Qur'an pada usia 10 tahun. Oleh karena itu materi menghafal Al-Qur'an sudah bisa diberikan pada anak usia 6 (enam) tahun sampai 14 (empat belas) tahun untuk melatih kemampuan menghafal dan kognitif peserta didik. Menghafal al qur'an menjadi sarana untuk mengenal dan mengetahui bahasa al qur'an yang menjadi dasar bagi pelajaran-pelajaran selanjutnya seperti belajar fiqih, tafsir dan ulumul qur'an. Selain itu pada usia anak 6 (enam) tahun sampai 14 (empat belas) tahun, mata pelajaran olahraga juga masih disarankan oleh Ibnu Sina. Namun demikian, oleh raga pada anak seusia 6 (enam) tahun sampai 14 (empat belas) tahun sudah

${ }^{14} \mathrm{Abu}$ 'Ali al-Husin ibn 'Ali Ibn Sina, Al-Siyasah fiy...., hlm. 321.

${ }^{15} \mathrm{Abu}$ 'Ali al-Husin ibn 'Ali Ibn Sina, Al-Siyasah fiy ..., hlm. 159.

${ }^{16} \mathrm{Abu}$ 'Ali al-Husin ibn 'Ali Ibn Sina, Al-Siyasah fiy...., hlm. 177 
pada tahap olahraga yang membutuhkan keahlian dan sesuai dengan usia anak tersebut. Akan berbeda jenis dan tingkat kesukaraannya jika dibandingakan dengan olahraga pada usia di bawahnya.

\section{Kurikulum Usia 14 (empat belas) Tahun Ke Atas}

Ibnu Sina menganjurkan kepada para pendidik agar memilih jenis pelajaran yang berkaitan dengan keahlian anak didik untuk menguasai bidang keilmuan. Mata pelajaran yang dimaksud di atas dibagi ke dalam mata pelajaran yang bersifat teoritis dan praktis. Ibn Sina terpengaruh oleh pemikiran filsuf Yunani Kuno (Aristoteles) yang juga membagi ilmu secara teoritis dan praktis:

Ilmu teoritis: (a) ilmu tabi'i (mencakup ilmu kedokteran, astrologi, ilmu firasat, ilmu sihir (tilsam) ilmu tafsir mimpi, ilmu niranjizat, dan ilmu kimia), (b) ilmu matematika, (c) ilmu ketuhanan, disebut paling tinggi (mencakup ilmu tentang cara-cara turunnya wahyu, hakikat jiwa pembawa wahyu, mu'jizat, berita ghaib, ilham, dan ilmu tentang kekekalan ruh, dan sebagainya). ${ }^{17}$

Selanjutnya Ilmu praktis: ilmu akhlak yang mengkaji tentang tentang cara-cara pengurusan tingkah laku seseorang, ilmu pengurusan rumah tangga, yaitu ilmu yang mengkaji hubungan antara suami istri, anak-anak, pengaturan keuangan dalam kehidupan rumah tangga, serta ilmu politik yang mengkaji tentang bagaimana hubungan antara rakyat dan pemerintahan, kota dengan kota, bangsa dan bangsa. ${ }^{18}$ Jika diperhatikan secara seksama, dapat dilihat bahwa pemikiran Ibnu Sina tersebut juga diimplementasikan disekolah-sekolah tingkat SMA/MA/dan SMK. Dimana anak usia ini telah melakukan penjurusan keahlian di Sekolah Menengah. Penjurusan IPA, IPS, dan bahasa merupakan penjurusan berdasarkan minat, bakat dan potensi yang dimiliki oleh peserta didik.

Selanjutnya, implementasi kurikulum dari pemikiran Ibnu Sina ${ }^{19}$ diatas menurut penulis, dapat dilihat pada lembaga-lembaga pendidikan sebagai berikut: Kurikulum disusun berdasarkan kebenaran Wahyu dan kebenaran Ilmu pengetahuan, Menggunakan Penjenjangan, dan sistem klasikal, Pengembangan kurikulum di dasarkan pada usia dan tahap perkembangan anak, Pemberian materi ajar dilakukan secara bertahap, sesuai dengan potensi dan karakteristik peserta didik, Kurikulum disusun secara terintegrasi (integrasi-interkoneksi),

${ }^{17}$ Abu 'Ali al-Husin ibn 'Ali Ibn Sina, Tis’u Rasa’'il, (Mesir: Dar al- Ma'arif, 1994), hlm. 231

${ }^{18} \mathrm{Abu}$ 'Ali al-Husin ibn 'Ali Ibn Sina, Tis'u Rasa'il,..... hlm. 432.

${ }^{19}$ Penulis berkeyakinan bahwa Ibnu Sina selain merupakan tokoh pemikir Muslim beraliran Religious-Rasional, Beliau juga condong pada pemikiran Pragmatis/Fungsional, jika penulis merujuk pada pemikiran Ibnu Sina di atas dalam karyanya Abu 'Ali al-Husin ibn 'Ali Ibn Sina, Al-Siyasah fiy al-Tarbiyah, (Mesir: Dar al-Ma'arif, 1994) 
Kurikulum juga menjawab kepentingan dan kebutuhan pasar (bersifat pragmatis).

\section{Konsep Pendidik Menurut Ibnu Sina}

Pendidik yang baik adalah pendidik yang cakap secara intelektual, akhlak dan professional. Konsep pendidik yang dimaksudkan oleh Ibnu Sina guru yang cakap adalah guru yang berakal cerdas, beragama, mengetahui cara mendidik akhlak, cakap dalam mendidik anak, berpenampilan tenang, jauh dari berolokolok dan main-main di hadapan muridnya, tidak bermuka masam, sopan, santun, bersih dan suci murni. ${ }^{20}$ Jika dilihat Ibnu Sina memiliki pemikiran dan konsep revolusioner. Ibnu Sina menyarankan guru harus memiliki kompetensi personal, professional, sosial, Emosional dan Spiritual seperti apa yang diamanatkan dalam Undang-undang Nomor 14 tahun 2005 tentang Guru dan Dosen. Kompetensi personal dapat dilihat dalam penjelasanya bahwa guru harus berpenampilan tenang, sopan santun jauh dari berolok-olok. Kompetensi professional dapat dilihat pada pendapatnya guru harus cerdas dan mengetahui cara mendidik akhlak, cakap dalam mendidik anak. Kompetensi emosional dan spiritual dapat dilihat dari pendapatnya bahwa guru harus bersih dan suci murni, beragama, dan berpenampilan tenang.

Ibnu Sina juga menekankan agar seorang pendidik tidak hanya mengajarkan dari segi teoritis saja kepada anak didiknya, melainkan juga melatih segi keterampilan, mengubah budi pekerti dan kebebasannya dalam berfikir. Ia juga menekankan adanya perhatian yang seimbang antara aspek penalaran (kognitif) yang diwujudkan dalam pelajaran bersifat pemahaman; aspek penghayatan (afektif) yang diwujudkan dalam pelajaran bersifat perasaan; dan aspek pengamalan (psikomotorik) yang diwujudkan dalam pelajaran prektek.

\section{Konsep Metode Pendidikan Menurut Ibnu Sina}

Adapun konsep metode pengajaran yang diinginkan Ibnu Sina, bahwa suatu materi pelajaran tertentu tidak akan dapat dijelaskan kepada subjek didik dengan satu cara saja, melainkan harus dicapai dengan berbagai cara yang sesuai dengan perkembangan psikologisnya. ${ }^{21}$ Beliau menegaskan bahwa dalam penyampaian materi tersebut, hendaknya disesuaikan dengan sifat materi.

Ibnu Sina menginginkan metode talqin, demontrasi, pembiasaan, teladan, diskusi, magang dan penugasan. ${ }^{22}$ Metode talqin, digunakan untuk mengajar

\footnotetext{
${ }^{20}$ Abuddin Nata, Pemikiran Para Tokoh..., hlm. 77.

${ }^{21}$ Abuddin Nata, Pemikiran Para Tokoh..., hlm. 76

${ }^{22}$ Abuddin Nata, Pemikiran Para Tokoh..., hlm. 75
} 
membaca al-Qur'an. Metode demontrasi, mengajar menulis. Sementara metode pembiasaan digunakan untuk cara mengajar etika dan Akhlak metode diskusi, ia menggunakan untuk cara penyajian pelajaran kepada subjek didik. Metode magang, ia menggunakan dalam kegiatan pengajaran yang dilakukan. metode penugasan, untuk memberikan pengalaman pada anak didik untuk mengerjakan tugas. Jika diperhatikan lebih lanjut, Ibnu Sina menginginkan metode yang berbeda dalam menghadapi materi pelajaran. Hal ini mengindikasikan bahwa Ibnu Sina memperhatikan karakter materi pelajaran dalam menggunakan metode tertentu. Selain itu Ibnu Sina menginginkan Metode targhîb dan tarbîb yang dalam pendidikan modern dikenal istilah reward yang berarti ganjaran, hadiah, penghargaan atau imbalan dan merupakan salah satu alat pendidikan dan berbentuk reinforcement yang positif, sekaligus sebagai motivasi yang baik.

\section{PEMIKIRAN FILOSOSFIS IBNU SINA DAN RELEVANSINYA DALAM PENDIDIKAN ISLAM KONTEMPORER}

Berdasarkan pemikiran filosofis Ibnu Sina tentang konsep pendidikan, tujuan, kurikulum, pendidik dan peserta didik dalam pendidikan Islam, dapat dirumuskan konsep pendidikan Islam sebagai berikut:

Al-Qur'an dan konsep tauhid sebagai Basis Pendidikan Islam. AlQur'an merupakan kalam tuhan yang kebenarnya bersifat absolut dan tidak diragukan. Al-Qur'an merupakan sumber nilai, norma dan didalamya terdapat ayat-ayat pengetahuan. Ibnu Sina yang merupakan tokoh filosof muslim yang melandaskan pemikirannya pada kebenaran kalam tuhan. Sehingga beliau termasuk kalangan pemikir religious-rasional.

Pendidikan Islam dilaksanakan sejak dini. Pendidikan Islam harus diberikan secara langsung maupun tidak langsung secara Dini. Sebagaimana konsep pemikiran Ibnu Sina bahwa pada anak usia dini sudah harus diberikan pendidikan denganmateri-materi yang sesuai dengan kondisinya. Hubungannya dengan pendidikan kontemporer, di Indonesia contohnya elah lahir pendidikanpendidikan Usia dini seperti Taman Kanak-kanak.

Pendidikan Non Dikotomis. Ibnu Sina menginginkan konsep pendidikan agamis dan rasional. Individu harus memiliki pengetahuan keagamaan dan pengembagan kapasitas intelektual. Ibnu sina tidak membagi ilmu berdasarkan status kewajiban mempelajarinya (seperti Fardhu 'Ain dan Qifayah). Beliau menginginkan peran akal harus dikembangkan lebih optimal dalam dunia pendidikan.

Selanjutnya, Pendidikan interkoneksi-integrasi. Pendidikan integrasi interkoneksi menginginkan tidak ada pertentangan antara ilmu-ilmu agama 
dan ilmu umum. Mereka keduanya harus tercipta secara damai dan harmonis. Lembaga Pendidikan Islam khususnya pendidikan tinggi di Indonesia telah melahirkan konsep-konsep integrasi tersebut. Seperti UIN Sunan Kalijaga Yogyakarta dengan konsep intergrasi-interkoneksi, UIN Syarif Hidayatullah Jakarta dan UIN Malang. Konsep interkoneksi-integrasi ini setidaknya selaras dengan konsep pendidikan Ibnu Sina.

Pendidikan karakter dan Akhlak. Selain menjadi seorang ilmuwan besar Ibnu Sina juga sebagai tokoh yang banyak mengetahui tentang tafsir al quran. Beliau menjelaskan tentang konsep manusia sebagai mahluk ciptaan tuhan. Beliau juga menekankan aspek akhlak dan moral manusia. Relevan dengan pemikirannya tersebut di Indonesia telah menggaungkan pendidikan karakter dan moral bangsa.

Pendidikan dilaksanakan secara berjenjang. Di Indonesia dalam sistem pendidikan Nasional dikenal dengan penjenjanga pendidikan, yaitu pendidikan dasar, menengah dan pendidikan Tinggi. Juga diselenggarakan pendidikan berdasarkan jenisnya, pendidikan umum, vokasional dan kegamaan. Konsep tersebut sesuai dengan pemikiran Ibnu Sina bahwa penddikan dilakukan secara berjenjang dan diberikan sesuai keahlianya serta sesuai dengan karakteristik: potensi, minat, dan bakat anak didik.

\section{DAFTAR PUSTAKA}

Amin Abdullah, 2009, Falsafah Kalam di Era Postmodernisme (Yogyakarata: Pustaka Pelajar).

Abdurrahman Mas'ud, 2007, Menggagas Format Pendidikan Nondikotomik (Yogyakarta: Gama Media).

Al-Syaibany, 1979, Filsafat Pendidikan Islam, terj. Hasan Langgulung, (Jakarta: Bulan Bintang).

Philip K. Hitti, 1974, History of The Arab, ed. X, (Great Britain: Oxford University Press).

Muhammad Tolhah Hasan, 2006, Dinamika Pemikiran tentang Pendidikan Islam, (Jakarta: Lantabora Press).

Ahmad Fuad al- Ahwani, 1997, Filsafat Islam, (Jakarta: Pustaka Firdaus).

Imam Tholkhah \& Ahmad Barizi, 2004, Membuka Jendela Pendidikan; Mengurai Akar Tradisi dan Integrasi Keilmuan Islam, (Jakarta: PT Raja Grafindo Persada). 
Jalaluddin, 1996, Filsafat Pendidikan Islam, (Jakarta: PT. Raja Grafindo Persada). Hasan Langhulung, 1995, Manusia dan Pendidikan, cet. III. (Jakarta: Pustaka al-Husna).

Abu 'Ali al-Husin ibn 'Ali Ibn Sina, 1994, Al-Siyasah fiy al-Tarbiyah, (Mesir: Dar al-Ma'arif).

Abuddin Nata, 2001, Pemikiran Para Tokob Pendidikan Islam: Seri Kajian Filsafat Pendidikan Islam, cet. II, (Jakarta: Rajawali Press).

Abu 'Ali al-Husin ibn 'Ali Ibn Sina, 1994, Tis’u Rasa’il, (Mesir: Dar al- Ma'arif. 